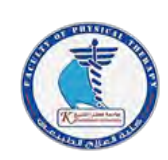

\title{
Effect of Labor on Pelvic Floor Muscles Strength
}

\author{
Mohamed A. Awad 1, Afaf M. Botla ${ }^{1}$, Amir A. Gabr ${ }^{2}$, Dalia M. Emara ${ }^{1 *}$ \\ ${ }^{1}$ Department of Woman 's Health, Faculty of physical therapy, Cairo University, Egypt. \\ ${ }^{2}$ Department of Gynecology and Obstetrics, Faculty of Medicine, Cairo University, Egypt.
}

\author{
*Correspondence to \\ Dalia M. Emara \\ Department of Woman's \\ Health, Faculty of \\ physical therapy, Cairo \\ University, Egypt. \\ Tel: 01000506013 \\ Email; \\ demara79@gmail.com
}

Published online:

March-2020

\begin{abstract}
:
Purpose: to evaluate the effect of labor on pelvic floor muscles strength.

Methods: Two hundred pregnant women at beginning of the $9^{\text {th }}$ month of pregnancy were selected randomly from antenatal care clinic of Kasr Al-Aini University Hospital in Cairo, Cairo University. Their ages were ranged from 25 to 35 years old and their body mass index was not exceeding $35 \mathrm{~kg} / \mathrm{m}^{2}$. They were Primigravida and Multigravida. Women who had history of pelvic disease, any previous pelvic operations, diabetes mellitus, history of abortion and history of preeclampsia or smokers and alcohol abusers are excluded from the study.

133 women delivered normal labor (55 primipara and 78 multipara) (Group A) and 67 women delivered by cesarean section (29 primipara and 38 multipara) (Group B). Pelvic floor muscles strength was evaluated for all women by using TG Myo feedback $420 \mathrm{v}$ at beginning of the $9^{\text {th }}$ month of pregnancy and after 6 weeks postnatal.

Results: Results of this study found that there was a statistically highly significant decrease $(\mathrm{P}<0.01)$ in pelvic floor muscles strength in both groups $\mathrm{A}$ and $\mathrm{B}$ after 6 weeks postnatal with percentage of decrease $30 \%$ and $9 \%$ respectively. After 6 weeks postnatal there was a statistical high significant difference between the mean value of pelvic floor muscles strength between both groups $\mathrm{A}$ and $\mathrm{B}$ with more decrease in group A .
\end{abstract}

Conclusion: It can be concluded that normal labor markedly decreases the pelvic floor muscles strength than cesarean section delivery.

Key words: Labor - Pelvic floor muscles.

Pelvic floor dysfunction is a general term that describes a wide range of functional clinical problems that are anatomically grouped. These are classified to anterior pelvic compartments symptoms, mostly concerned with urinary and sexual function. Two of the most common symptoms of anterior PFD are urinary incontinence (UI) and genital prolapse (GP). Posterior compartment symptoms are related to colorectal function. The most common symptoms are anal incontinence (AI) (2).

Pelvic floor dysfunction (PFD) is a disorder generally affects females. It is a common disorder threatened the quality of life (QOL) of at least 1/3 of adult women of all ages. Neural, hormonal and mechanical factors play a major role in the development of PFD (3).

Vaginal delivery can destroy the pudendal nerve, levator ani muscle, fascial pelvic organ supports and also can destroy the external and internal anal 
sphincters; these changes can reduce PFMs strength which lead to increase bladder and urethral sphincters mobility (4).

Physiotherapists assess pelvic floor muscles tone with both manual examination and EMG. Pelvic floor muscles assessment determines muscles tone during activity and relaxation, contractile amplitude and muscle endurance (5).

The main goal is to rehabilitate the pelvic floor by increasing awareness and proprioception, improving muscles discrimination and relaxation, normalizing muscle tone, enhance flexibility of the tissues at the vagina, decrease pain and remove fear of vaginal penetration. These goals achieved through pelvic floor re-education, electromyography (EMG) biofeedback, electrical stimulation, manual techniques and insertion techniques (6).

The combination of biofeedback and manual techniques helps women how to contract and relax their pelvic floor muscles. Moving a biofeedback vaginal sensor in an in-and-out motion increases the awareness of women to contract and relax when there is movement in the vagina. Visual feedback from the computer screen, verbal feedback from the therapist, and the physical "sensory" feedback from movement of the therapist's fingers in the vagina, all complement one another to teach women about pelvic floor musculature (7).

Biofeedback is the process of monitoring, amplifying, and conditioning of physiological signals, then present it to the women to be able to observe changes in the screen and gradually can control the contraction voluntarily. So, biofeedback is used to train subject to decrease, increase and stabilize muscles tension through proportional changes in a moving meter, bar graph, polygraph display or an auditory tone (8).

\section{Patients and Methods}

\subsection{Participants}

Two hundred pregnant women at beginning of the $9^{\text {th }}$ month of pregnancy were selected randomly from antenatal care clinic of Kasr Al-Aini University Hospital in Cairo, Cairo University. The study period was from July 2018 to Feb 2019. They were selected on the following criteria: Their ages were ranged from 25-35 year and their body mass index did not exceed $35 \mathrm{Kg} / \mathrm{m}^{2}$. They were primigravida and multigravida. Women who had history of pelvic disease, any previous pelvic operations, diabetes mellitus, history of abortion and history of pre-eclampsia or smokers and alcohol abusers are excluded from the study.

Postnatal the type of labor divided them into two groups: Group A: 133 women delivered normal labor (55 primipara and 78 multipara). Group B: 67 women delivered by cesarean section (29 primipara and 38 multipara). Pelvic floor muscles strength was evaluated for all women by using TG Myo feedback $420 \mathrm{v}$ at beginning of the $9^{\text {th }}$ month of pregnancy and after 6 weeks postnatal.

\subsection{Instrumentation:}

2.2.1. Standard weight scale. It was used to measure weight and height to calculate body mass index (BMI) for each woman.

2.2.2. TG. Myo feedback 420v. It was used to assess pelvic floor muscles strength at beginning of the $9^{\text {th }}$ month of pregnancy and after 6 weeks postnatal by using vaginal electrode. This electrode consists of rubber chamber connected to the main unit of TG Myo feedback $420 \mathrm{v}$ by a rubber tube.

2.2.3. Condoms. It was used to cover the TG Myo feedback $420 v$ electrode before application to avoid ascending infections.

2.2.4. KY gel. It was applied over the electrode for lubrication.

\subsection{Procedures of the study:}

The study was performed under approval of the ethical committee of faculty of physical therapy, Cairo University.

All pregnant women were given a full explanation of the protocol of the study and consent form was signed for each woman before participating in the study.

2.3.1. Weight and height measurements:

Weight and height were measured while the woman wearing light clothes to calculate the BMI before participating in the study according to the following equation:

BMI $=$ weight $/$ height $^{2}\left(\mathrm{Kg} / \mathrm{m}^{2}\right)$.

2.3.2. Pelvic floor muscles strength:

2.3.2.1. Preparation of the women:

-Each woman was informed to evacuate her bladder before the evaluation session to be relaxed.

-All women were given a demonstration about voluntary muscle control by using an electrode in neutral muscles (muscles of hand grip), women were asked to contract, relax and observe the response to both contraction and relaxation on the screen.

2.3.2.2. Relaxation techniques:

Before recording any data, the patient was asked to relax to avoid apprehension and fear as well as to evaluate the level of female awareness through the following techniques:

-Mental relaxation. With eyes and mouth, gently closed, patients counted from 10 to 0 for 5 sets.

-Physical relaxation. Through breathing exercise as the following:

A-Diaphragmatic breathing. The woman was asked to inhale slowly go through the nose (keeping the shoulders relaxed), feeling the airflow in, and raising her abdomen upward. Then let the air slowly out through the mouth with a sigh, feeling the tension going with it. After three times repetition of deep 
breathing, each woman was given a period of rest equal to the period of breathing was given to avoid hyperventilation.

B-Costal breathing. The woman was asked to take deep inspiration from the nose, open out the ribs and expire the air from the mouth with a sigh. After three times repetition of deep breathing, each woman was given a period of rest equal to the period of breathing was given to avoid hyperventilation.

2.3.2.3. Evaluative recording step:

-Using TG Myo Feedback 420v. The women lie in a comfortable crock lying position with soft pillow behind the head and small cushions placed under the lower back and hips.

-Increased pelvic floor muscles awareness as the following, the women were asked to perform pelvic floor muscles exercise to be able to contract and relax these muscles as the following "contract as if you control the bowel action and urethral orifice action (concentrate in this action) hold then relax and repeat for about 10 times".

-Then the TG Myo feedback 420v vaginal electrode was cleaned, covered with condom, lubricated by KY gel, and introduced gently inside the vagina to evaluate the vaginal closure pressure, and to measure the deeper internal pelvic floor muscles strength.

-The internal probe promoted proprioception, and aided in muscles awareness for every woman.

-The therapist explained the TG Myo feedback display to the women. The therapist might say, "A relaxed muscle will light up fewer bars, and contracting muscle will light up many bars". Try to relax the muscles as much as possible. The numbers of bars seen at the bottom of the screen indicated the activity of the muscles.

-TG Myo feedback display became visible. Begin timing a 1-minute resting base line using a wristwatch. Then the evaluation should not be interrupted and talking should be kept at a minimum to get a clear base line reading. Inconsistent baseline resting tone indicates an inability to relax the pelvic floor muscles or hypertonicity. It may also indicate an inability to recognize the difference between contracted and relaxed muscles or neuromuscular incoordination.

-Women were asked to contract the pelvic floor muscles as hard as she can around the electrode then relax; this step was repeated three times. Then the mean of the 3-reading data was calculated and recorded in the data sheet. This procedure was repeated at beginning of the $9^{\text {th }}$ month of pregnancy and after 6 weeks postnatal.

-The data of the TG Myo feedback was recorded in the computer memory. This data reflected the strength of pelvic floor muscles.

Data analysis

Results are expressed as mean, standard deviation. Comparison between values of different variables in the two studied groups was performed using unpaired $t$ test. Pairwise comparison of pelvic floor muscles strength at beginning of the $9^{\text {th }}$ month of pregnancy and after 6 weeks postnatal within the same group was performed using paired $t$ test. The level of significance fixed to $5 \%(\mathrm{P}<0.05)$.

\section{Results}

\subsection{General characteristics of the women:}

There was no statistical significant difference between mean value of age, weight, height and BMI between group $\mathrm{A}$ and group $\mathrm{B}$ with $\mathrm{t}$ value $=(0.836,-0.176$, 0.054 and 0.082$)$ respectively and $\mathrm{P}$ value $=(0.404$, $0.861,0.967$ and 0.945 ) respectively (Table 1 ).

\section{Table (1): General characteristics of both groups A} and $B$.

\begin{tabular}{ccccc} 
& Group A & Group B & $\mathrm{t}$ & $\mathrm{p}$ \\
\cline { 2 - 3 } & Mean \pm SD & Mean \pm SD & value & value \\
\hline Age & $28.59 \pm 2.247$ & $28.87 \pm 2.417$ & 0.836 & 0.404 \\
Weight & $85.89 \pm 7.594$ & $85.79 \pm 8.478$ & 0.176 & 0.861 \\
Height & $163.98 \pm 5.246$ & $163.86 \pm 5.352$ & 0.054 & 0.967 \\
BMI & $31.94 \pm 2.790$ & $31.95 \pm 2.861$ & 0.082 & 0.945 \\
\hline
\end{tabular}

\subsection{Pelvic floor muscles strength:}

\subsubsection{Within groups:}

Paired sample t-test showed that there was a statistical highly significant decrease of pelvic floor muscles strength mean value after 6 weeks postnatal in comparison to $9^{\text {th }}$ month of pregnancy mean value in both groups $\mathrm{A}$ and $\mathrm{B}$ with $\mathrm{t}$-value = (35.497and14.255 respectively) and $\mathrm{P}$-value $=$ ( 0.0001 and 0.0001 respectively) with percentage of decrease of (30\% and $9 \%$ respectively) (Table 2 and Figure 1).

\subsubsection{Between groups:}

In the $9^{\text {th }}$ month of pregnancy, as shown in (Table 2 and Figure 1) there was a statistical non-significant difference between the mean value of pelvic floor muscles strength between group A and group B with $\mathrm{t}$ value $=-0.665$ and $\mathrm{p}$ value $=0.507$.

After 6 weeks postnatal, as shown in (Table 2 and Figure 1) there was a statistical high significant difference between the mean value of pelvic floor muscles strength between group A $(44.3 \pm 21.291)$ and group $\mathrm{B}(58.96 \pm 19.569)$ with $\mathrm{t}$ value $=-5.07$ and $\mathrm{p}$ value $=0.0001$.

3.3. Comparison of the mean values of differences of decrease in pelvic floor muscles strength between both groups A and B:

The comparison between the mean values of differences of decrease in $9^{\text {th }}$ month of pregnancy and after 6 weeks postnatal in the pelvic floor muscles strength in group A and group B showed that there was a highly significant difference between 
both groups with $\mathrm{t}$-value $=19.84$ and $\mathrm{P}$-value $=0.0001$ (more decrease in group A). (Table 3 and Figure 2).

Table (2): Pelvic floor muscles strength in $9^{\text {th }}$ month of pregnancy and after 6 weeks postnatal in both groups $A$ and $B$ :

\begin{tabular}{|c|c|c|c|c|}
\hline $\begin{array}{c}\text { Pelvic } \\
\text { floor }\end{array}$ & $9^{\text {th }}$ pregnancy & $\begin{array}{c}\text { After } 6 \text { weeks } \\
\text { postnatal }\end{array}$ & \multirow{2}{*}{$\begin{array}{cc}\mathrm{t}- & \mathrm{P}- \\
\text { value } & \text { value }\end{array}$} & \multirow{2}{*}{$\begin{array}{c}\% \text { of } \\
\text { change }\end{array}$} \\
\hline $\begin{array}{l}\text { Muscles } \\
\text { Strength }\end{array}$ & Mean \pm SD & Mean \pm SD & & \\
\hline $\begin{array}{c}\text { Group } \\
\text { A }\end{array}$ & $62.88 \pm 20.854$ & $44.3 \pm 21.291$ & 35.4970 .0001 & $30 \%$ \\
\hline $\begin{array}{c}\text { Group } \\
\text { B }\end{array}$ & $64.71 \pm 17.95$ & $58.96 \pm 19.569$ & 14.2550 .0001 & $9 \%$ \\
\hline MD & -1.83 & -14.66 & & \\
\hline t-value & -0.665 & -5.07 & & \\
\hline $\mathrm{P}$ - value & 0.507 & 0.0001 & & \\
\hline
\end{tabular}

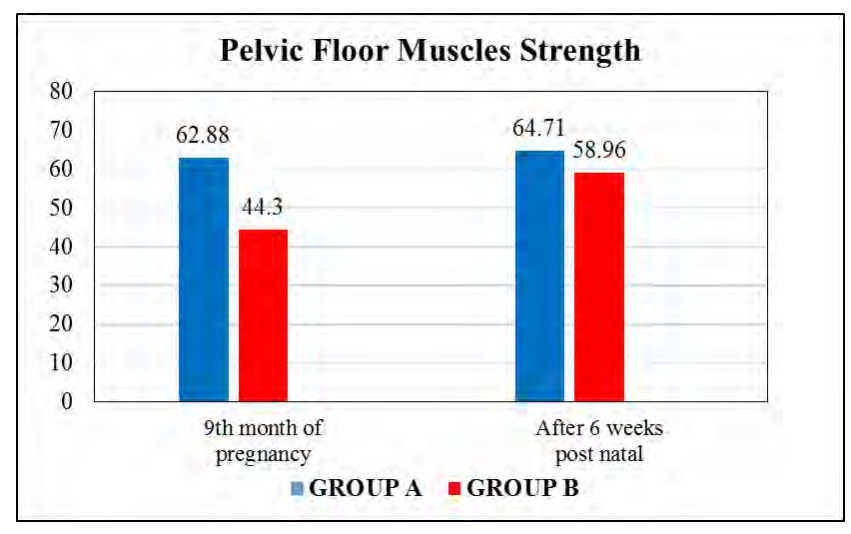

Fig. (1): Mean values of Pelvic floor muscles strength in $9^{\text {th }}$ month of pregnancy and after 6 weeks postnatal in both groups $A$ and $B$.

Table (3): Comparison of the mean values of difference of decrease from $9^{\text {th }}$ month of pregnancy to after 6 weeks postnatal between both groups $A$ and $B$ :

Pelvic floor Differences of decrease between $9^{\text {th }}$

\begin{tabular}{ccc} 
Muscles Strength & Group A & Group B \\
\hline Mean \pm SD & $18.58 \pm 5.234$ & $5.75 \pm 4.034$ \\
MD & \multicolumn{2}{c}{12.83} \\
t-value & 19.415 & \\
P- value & 0.0001 & \\
\hline
\end{tabular}

\section{Discussion}

Vaginal delivery threatened the pelvic floor muscles function such as in ability to maintain both urinary and anal continence, as the baby emerges, the largest diameter part of the head loads and lengthens the pelvic floor muscles, connective tissues and nerves. It is likely to know the causes of pelvic floor dysfunction by assessing the stretching and tearing of pelvic fascia and muscles and accidental trauma to the pudendal nerves (9).

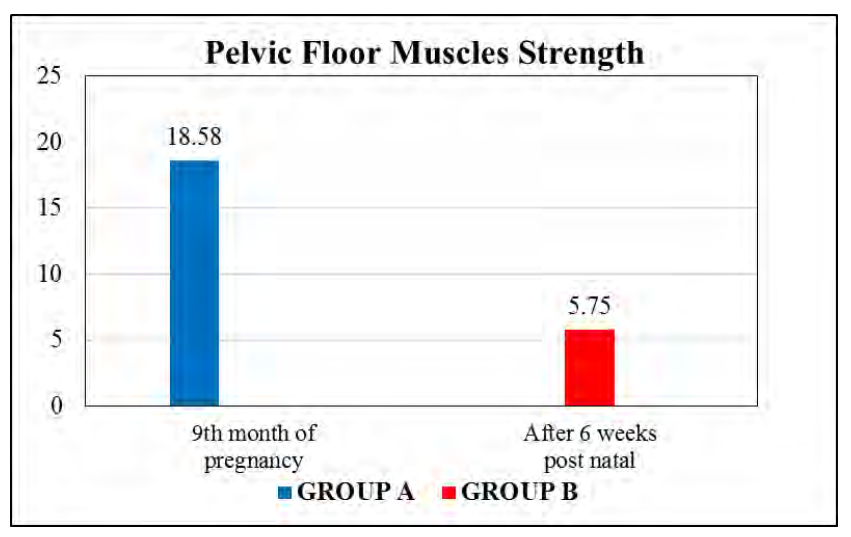

Fig. (2): Mean values of differences of decrease from 9th month of pregnancy to after 6 weeks postnatal between both groups $A$ and $B$.

Vaginal delivery destroys the pudendal nerve, the levator ani muscle, pelvic supports and the anal sphincters; this damage affects pelvic floor muscles strength (10).

This study was conducted to evaluate the effect of labor on pelvic floor muscles strength. Two hundred pregnant women at beginning of the $9^{\text {th }}$ month of pregnancy were selected randomly from antenatal care clinic of Kasr Al-Aini University Hospital in Cairo, Cairo University. 133 women delivered normal labor (55 primipara and 78 multipara) (Group A) and 67 women delivered by cesarean section (29 primipara and 38 multipara) (Group B). Pelvic floor muscles strength was evaluated for all women by using TG Myo feedback 420v at beginning of the $9^{\text {th }}$ month of pregnancy and after 6 weeks postnatal.

The results of this study found that, within groups there was a statistically highly significant decrease $(\mathrm{P}<0.01)$ in pelvic floor muscles strength in both groups A and B after 6 weeks postnatal with percentage of decrease $30 \%$ and $9 \%$ respectively. After 6 weeks postnatal there was a statistical high significant difference between the mean value of pelvic floor muscles strength between both groups $\mathrm{A}$ and $\mathrm{B}$ with more decrease in group $\mathrm{A}$.

The weakness of the pelvic floor muscles after labor can be explained by the following reasons; Connective tissue in the area of the urogenital organs is sensitive to hormones. The vaginal membrane becomes more stretched to allow the dilatation of natural birth canal during normal labor so, genital prolapse often occurs during pregnancy. Laxity in the ligaments, muscles and pelvic supports may reduce the elastic closure force leading to urine loss on effort. Loss of membranes support may cause gravity 
to stimulate the nerve endings at the bladder base so causing premature activation of micturition reflex expressed as symptoms of bladder instability (11).

The results of the study agreed with (12) who compared the pelvic floor muscles strength after normal labor and cesarean section delivery. 100 women, included in 50 healthy normal labor women, and healthy cesarean section women. Pelvic floor muscles strength was evaluated using digital palpation and portable perineometer. Results concluded that vaginal delivery may cause weakness of the pelvic floor muscles.

The results of this study were supported by (13) who compared between pelvic floor muscles activation in nulliparous and multiparous women after delivery, by assessing the relationship between electrical activity, vaginal palpation and perineal flexibility (Epi-no). The electrical activity and muscles strength of the pelvic floor muscles of the multiparous women were destroyed in relation to the nulliparous women and the perineal flexibility was lower in nulliparous women, with positive relationship between surface EMG and the modified Oxford scale.

Also, the results supported by (14) who compared the pelvic floor muscles strength after normal vaginal delivery and cesarean section delivery. Results showed that normal vaginal delivery decreases pelvic floor muscles strength more than cesarean section delivery.

A recent study of nulliparous women followed through pregnancy and 18 months postnatal in Australia founded that, increased UI among women who have vaginal delivery when compared to cesarean section, and also founded that, increased second stage of labor duration and instrumental delivery increases postnatal UI (15).

Another cohort study founded that there was an increased risk of UI in the vaginal birth when compared to the cesarean section delivery. In addition, the vaginal birth women have genital prolapse when compared to women delivered by cesarean section, with the greatest affection founded in the operative vaginal delivery women (16).

(17) showed that, when nulliparous pregnant women at 36 weeks of gestation and at the 6thweek of postnatal were assessed, $46 \%$ were developed some degrees of pelvic organ prolapse, with no difference in the rate of development between vaginal and cesarean section delivery.

The results of this study agreed with (18) who found that the risk of levator defect after vaginal delivery is more than seven times higher than after caesarean section. Despite this, emergency caesarean section seems to have no complete preventive effect on levator aini muscle trauma.

The results of this study also, agreed with (19) who showed that, compared spontaneous vaginal delivery and cesarean delivery had a significant lower degree of SUI and POP, while operative vaginal delivery had a significant higher incidence of anal incontinence (AI) and POP.

The results of this study also, agreed with (20) who found that, the study of multiparous vaginal delivery women a double risk of developing symptoms of stress incontinence compared with women delivered exclusively by cesarean section.

The results of this study also, agreed with (21) who found that, the incidence of moderate or severe UI in the vaginal birth was higher than cesarean delivery at 3-5 days as, pelvic floor muscles strength is significantly reduced at 3-8 days after vaginal birth.

The results of this study also, agreed with (22) who showed that, cesarean section and vaginal delivery are associated with two-fold increase in the risk of long-term SUI, with an increase of $8 \%$ and its effect is largest in young women, and increased risk of UUI, with an increase of approximately $3 \%$.

The results of this study are not supported by the study of (23) who conducted a study of pelvic floor muscles strength in women of reproductive age (nulliparous) or those who had a caesarean section or normal vaginal delivery, there was a significant difference in pelvic floor muscles strength between normal vaginal and caesarean section delivery.

The results of this study are also not supported by (24) who did not find that vaginal birth women were more likely to report any SUI on self-report measures than those delivered by cesarean section at 6 months postnatal, and SUI varied between them. Vaginal birth women were more likely to leak than cesarean section women.

The results of this study are also not supported by (25) who showed that, women who delivered by lower segment cesarean section had urinary incontinence same as women with vaginal delivery.

\section{Conclusion}

Accordingly, it can be concluded that normal labor markedly decreases the pelvic floor muscles strength than cesarean section delivery.

Funding: Not funded.

\section{Conflict of Interests}

Authors declare no potential conflicts of interest.

\section{Acknowledgments}

We would like to thank all individuals who contributed to the completion of this work, especially participants.

\section{References}

1. Raizada V and Mittal RK. Pelvic floor anatomy and applied physiology. Gastroenterology clinics of North America. 2008; 37(3), 493-vii.

2. Quigley EM. Impact of pregnancy and parturition on the anal sphincters and pelvic 
floor. Best practice \& research clinical gastroenterology. 2007; 21(5), 879-891.

3. Buurman MBR and Lagro-Janssen ALM. Women's perception of postpartum pelvic floor dysfunction and their help-seeking behaviour: a qualitative interview study. Scandinavian journal of caring sciences. 2013; 27(2), 406-413.

4. Dietz $\mathrm{H}$ and Wilson P. Childbirth and pelvic floor trauma. Best Practice \& Research Clinical Obstetrics \& Gynaecology. 2005; 19(6), 913924.

5. Glazer H. Dysesthetic vulvodynia: Long-term follow-up after treatment with surface electromyography-assisted pelvic floor muscle rehabilitation. 2005; J Reprod Med., 45, 798802.

6. Binik Y, Bergeron S and Khalifa S. Dyspareunia. Principles and practice of sex therapy. 2000; 3rd Ed. New York, NY: The Guilford press.

7. Bergeron $\mathrm{S}$ and Lord MJ. The integration of pelvi-perineal re-education and cognitivebehavioural therapy in the multidisciplinary treatment of the sexual pain disorders. Sexual and Relationship Therapy. 2000; 18(2), 135-141.

8. Blanchard EB. Biofeedback: A Selective Review of Clinical Applications in. Behavioral Approaches to Medicine: Application and Analysis. 2013; 131.

9. Kapoor DS and Freeman RM. Pregnancy, childbirth and urinary incontinence. In: Haslam, J., Laycock, J. (eds) Therapeutic Management of Incontinence and Pelvic Pain. London: SpringerVerlag. 2008.

10. Davis K and Kumar D. Pelvic floor dysfunction: a conceptual framework for collaborative patient-centred care. Journal of advanced nursing, 43(6). 2003; 555-568.

11. Wijma J, Potters AEW, Wolf BT, Tinga DJ and Aarnoudse JG. Anatomical and functional changes in the lower urinary tract during pregnancy. BJOG: An International Journal of Obstetrics \& Gynaecology, 108(7). 2001; 726732.

12. Gameiro MO, Sousa VO, Gameiro LF, Muchailh RC, Padovani CR and Amaro JL. Comparison of pelvic floor muscle strength evaluations in nulliparous and primiparous women: a prospective study. Clinics, 66(8). 2011; 13891394.

13. Petricelli CD, Resende APM, Elito Júnior J, Araujo Júnior E, Alexandre SM, Zanetti MRD and Nakamura MU. Distensibility and strength of the pelvic floor muscles of women in the third trimester of pregnancy. BioMed research international. 2014.

14. Mendes EdPB, Oliveira SMJVd, Caroci AdS, Francisco AA, Oliveira SG and Silva RLd. Pelvic floor muscle strength in primiparous women according to the delivery type: crosssectional study. Revista Latino-Americana de Enfermagem, 2016; 24.

15. Gartland D, Donath S, MacArthur C and Brown SJ. The onset, recurrence and associated obstetric risk factors for urinary incontinence in the first 18 months after a first birth: An Australian nulliparous cohort study. BJOG. 2012; 119(11):1361-9. [PubMed] [Google Scholar]

16. Handa VL, Blomquist JL, McDermott KC, Friedman S and Munoz A. Pelvic floor disorders after vaginal birth: effect of episiotomy, perineal laceration, and operative birth. Obstet Gynecol. 2012; 119(2 Pt 1):233-9. [PMC free article] [PubMed] [Google Scholar.

17. Sze EH, sherard 3rd GB and Dolezal JM. Pregnancy, labor, delivery and pelvic organ prolapse. Obstet gynecol. 2002; 100:981 6.

18. Albrich S, Laterza R, Skala C, Salvatore S, Koelbl $\mathrm{H}$ and Naumann G. Impact of mode of delivery on levator morphology: a prospective observational study with three-dimensional ultrasound early in the postpartum period. BJOG. 2012; 119:51-61.

19. Joan L, Blomquist MD, Alvaro Muñoz $\mathrm{PhD}$ and Megan Carroll MS. Department of Gynecology, Greater Baltimore Medical Center, 6569 N Charles St, Ste 306, Baltimore, MD 21204 (jblomqui@gbmc.org). 2018.

20. Handa VL, Blomquist JL, Knoepp LR, Hoskey KA, McDermott KC and Muñoz A. Pelvic floor disorders 5-10 years after vaginal or cesarean childbirth. Obstet. Gynecol. 2011; 118, 777-784.

21. Peschers UM, Schaer GN, DeLancey JO and Schuessler B. Levator ani function before and after childbirth. Br J Obstet Gynaecol; 1997; 104:1004-8.

22. David W. Long-term Impact of Mode of Delivery on Stress Urinary Incontinence and Urgency Urinary Incontinence: A Systematic Review and Meta-Analysis European Urology, Volume 70, Issue 1, July, 2016; Pages 159-160.

23. Afshari $P$, Dabagh $F$, Iravani $M$ and Abedi $P$. Comparison of pelvic floor muscle strength in nulliparous women and those with normal vaginal delivery and cesarean section. International Urogynecology Journal, 2016; 1-5.

24. Evers EC, Blomquist JL, McDermott KC and Handa VL. Obstetrical anal sphincter laceration and anal incontinence 5-10 years after childbirth. Am J Obstet Gynecol. 2012; 207(5):425. [PMC free article] [PubMed] [Google Scholar]

25. Rortveit $G$ and Daltveit AK. Urinary incontinence after vaginal delivery or cesarean section. N Engl J Med.; 348:900-7Hokinson EC. Measurement of pain. The Lancet. 2003; 2(7889):1127-1131. 